\title{
Mechanisms of simvastatin-induced vasodilatation of rat superior mesenteric arteries
}

\author{
YULONG CHEN $^{1,2^{*}}$, HONGMEI ZHANG ${ }^{3 *}$, HUANHUAN LIU ${ }^{2}$ and AILAN CAO ${ }^{1,4}$ \\ ${ }^{1}$ Shaanxi Pharmaceutical Development Center, Shaanxi Pharmaceutical Holding Group Co., Ltd., \\ Xi'an, Shaanxi 710075; ${ }^{2}$ Shaanxi Key Laboratory of Ischemic Cardiovascular Disease, Institute of \\ Basic and Translational Medicine, Xi'an Medical University, Xi'an, Shaanxi 710021; ${ }^{3}$ Medical Record \\ Department, The First Affiliated Hospital of Xi'an Medical University, Xi'an, Shaanxi 710077; ${ }^{4}$ Preparation \\ Research Room, Shaanxi Chinese Medicine Institute, Xianyang, Shaanxi 712000, P.R. China
}

Received April 18, 2016; Accepted August 29, 2016

DOI: $10.3892 /$ br.2016.756

\begin{abstract}
Independent of its lipid-lowering properties, simvastatin (Sim) induces vasorelaxation; however, the underlying mechanisms have remained elusive. The aim of the present study was to investigate the vasorelaxant effects of Sim on rat superior mesenteric arteries and the mechanisms involved. The isometric tension of rat superior mesenteric arterial rings was recorded in vitro on a myograph. The results showed that Sim concentration-dependently relaxed the superior mesenteric artery rings with endothelium pre-contracted by phenylephrine hydrochloride [maximum relaxation $\left(\mathrm{E}_{\max }\right)=51.05 \pm 4.09 \%$; negative logarithm of the concentration that caused $50 \%$ of the maximum response $\left.\left(\mathrm{pD}_{2}\right)=4.17 \pm 0.18\right]$ or $\mathrm{KCl}\left(\mathrm{E}_{\max }=41.65 \pm 1.32 \% ; \mathrm{pD}_{2}=3.55 \pm 0.1\right)$. $\mathrm{N} \omega$-nitro-L-arginine methyl ester $(100 \mu \mathrm{M})$ significantly inhibited this effect, while it was not affected by $1 \mathrm{H}-[1,2,4]$ oxadiazolo[4,3-a]quinoxalin-1-one $(10 \mu \mathrm{M})$ and indomethacin $(5 \mu \mathrm{M})$. In artery rings without endothelium, vasorelaxation induced by $\mathrm{Sim}$ was attenuated by 4 -aminopyridine $(100 \mu \mathrm{M})$, but was not affected by barium chloride dehydrate $(10 \mu \mathrm{M})$, glibenclamide $(10 \mu \mathrm{M})$ and traethylammonium chloride (1 mM). Moreover, Sim also inhibited the contraction induced
\end{abstract}

Correspondence to: Professor Ailan Cao, Shaanxi Pharmaceutical Development Center, Shaanxi Pharmaceutical Holding Group Co., Ltd., 69 Keji 2nd Road, Xi'an, Shaanxi 710075, P.R. China

E-mail: caoailan0105@163.com

*Contributed equally

Abbreviations: PE, phenylephrine hydrochloride; Ach, acetylcholine chloride; 4-AP, 4-aminopyridine; eNOS, endothelial nitric oxide synthase; Gli, glibenclamide; Indo, indomethacin; $\mathrm{BaCl}_{2}$, barium chloride dehydrate; L-NAME, N $\mathrm{N}$-nitro-L-arginine methyl ester; NO, nitric oxide; ODQ, 1H-[1,2,4]oxadiazolo[4,3-a] quinoxalin-1-one; Sim, simvastatin; TEA, tetraethylammonium chloride; VSMCs, vascular smooth muscle cells

Key words: simvastatin, vasorelaxant effects, nitric oxide, $\mathrm{K}^{+}$ channel, $\mathrm{Ca}^{2+}$ influxs by increasing external calcium in $\mathrm{Ca}^{2+}$-free medium with added $\mathrm{KCl}(60 \mathrm{mM})$. These results suggested that Sim induces relaxation of superior mesenteric arterial rings through an endothelium-dependent pathway, involving nitric oxide release and also through an endothelium-independent pathway, involving the opening of voltage-dependent $\mathrm{K}^{+}$channels and blockade of extracellular $\mathrm{Ca}^{2+}$ influx.

\section{Introduction}

Simvastatin (Sim) is a drug widely used for the treatment of cardiovascular disease (CVD) $(1,2)$. Sim acts as an inhibitor of 3-hydroxy-methylglutaryl coenzyme A reductase, which is a rate-determining enzyme in the biosynthesis of cholesterol, and reduces the plasma levels of low-density lipoprotein (LDL) (3). Clinical studies have shown that treatment with Sim markedly decreased the incidence of cardiovascular events (4). While the lipid-lowering effect is a major mechanism of action of Sim against CVD, increasing evidence has demonstrated that other mechanisms are involved, including reduction of oxidative stress and vascular inflammation, improvement of endothelial function, and enhancement of the stability of atherosclerotic plaques (5). In addition, independent of its lipid-lowering properties, Sim induced vascular relaxation in the aorta and inferior mesenteric artery of rats (2). Moreover, Sim protected the vascular endothelium against damage induced by LDL or oxidized LDL, and relaxed the thoracic aorta in rats (6). However, the underlying mechanisms have remained to be fully elucidated.

Therefore, the present study was designed to explore the mechanisms by which Sim induces relaxation in the superior mesenteric artery of rats. It enhanced the current knowledge on the underlying mechanisms to contribute to the further development of cardiovascular drugs.

\section{Materials and methods}

Reagents. Phenylephrine hydrochloride (PE), acetylcholine chloride (ACh), N $\omega$-nitro-L-arginine methyl ester (L-NAME), $1 \mathrm{H}-[1,2,4]$ oxadiazolo[4,3-a]quinoxalin-1-one (ODQ), indomethacin (Indo), 4-aminopyridine (4-AP), barium chloride 
dehydrate $\left(\mathrm{BaCl}_{2}\right)$, glibenclamide (Gli), tetraethylammonium chloride (TEA), Triton X-100 and Sim were obtained from Sigma-Aldrich (St. Louis, MO, USA). ODQ, TEA, Gli, 4-AP and Sim were dissolved in Dimethylsulfoxide. All other compounds were dissolved in distilled water.

In vitro pharmacology. Thirty Sprague-Dawley rats (male, 8 weeks old, 300-350 g), which were obtained from the Animal Center of Xi'an Jiaotong University (Xi'an, China), were sacrificed by $\mathrm{CO}_{2}$ inhalation. The superior mesenteric artery was gently removed and freed from adhering tissue under a dissecting microscope. The endothelium was denuded by perfusion of the vessel with on Triton X-100 $(0.1 \%, \mathrm{v} / \mathrm{v})$ for $10 \mathrm{sec}$, followed by physiologic saline solution (PSS; $\mathrm{NaCl}$ $119 \mathrm{mM}, \mathrm{KCl} 4.6 \mathrm{mM}, \mathrm{NaHCO}_{3} 15 \mathrm{mM}, \mathrm{NaH}_{2} \mathrm{PO}_{4} 1.2 \mathrm{mM}$, $\mathrm{MgCl}_{2} 1.2 \mathrm{mM}, \mathrm{CaCl}_{2} 1.5 \mathrm{mM}$ and glucose $5.5 \mathrm{mM}$ ) for another $10 \mathrm{sec}$. The vessels were then cut into cylindrical segments of 1-3 $\mathrm{mm}$ in length. The segments were immersed in individual baths containing PSS $(5 \mathrm{ml})$ in a temperature-controlled $\left(37^{\circ} \mathrm{C}\right)$ myograph (Danish Myo Technology A/S, Aarhus, Denmark). The solution was continuously aerated with gas (containing $5 \% \mathrm{CO}_{2}$ and $95 \% \mathrm{O}_{2}$ ), resulting in a $\mathrm{pH}$ of 7.4 . Following mounting of the arterial segments, isometric tension was continuously recorded of using Chart software (ADInstruments, Oxford, UK). The segments were allowed to stabilize at a resting tone of $2 \mathrm{mN}$ for at least $1.5 \mathrm{~h}$, followed by immersion in a $\mathrm{K}^{+}$-rich $(60 \mathrm{mM})$ buffer solution with the same composition as the standard solution, except for $\mathrm{NaCl}$ being replaced by $\mathrm{KCl}$ to reach a final $\mathrm{K}^{+}$concentration of $60 \mathrm{mM}$ (KPSS). The potassium-induced contraction was used as a reference for contractile capacity, and only the segments which showed reproducible responses over $1.0 \mathrm{mN}$ to potassium were used. In another group, PE $(10 \mu \mathrm{M})$ was used instead of KPSS. After a sustained tension was obtained, $\operatorname{Sim}\left(10^{-10}-10^{-5} \mathrm{M}\right)$ was cumulatively added to the baths and concentration-response curves to Sim were constructed.

In the experiment involving endothelium, Ach $(10 \mu \mathrm{M})$ was added after pre-contraction with KPSS to test the completeness of endothelium denudation. An effective functional removal of the endothelium was indicated by absence of relaxation in response to Ach. The rings with endothelium showing $<30 \%$ relaxation in response to Ach were discarded (7). Furthermore, the artery rings with endothelium were pre-incubated with the cyclooxygenase inhibitor Indo $(5 \mu \mathrm{M})$, the guanylate cyclase inhibitor ODQ $(10 \mu \mathrm{M})$, the endothelial nitric oxide (NO) synthase (eNOS) inhibitor L-NAME $(100 \mu \mathrm{M})$, or with the with the $\mathrm{K}^{+}$channel blockers 4 -AP $(100 \mu \mathrm{M}), \mathrm{BaCl}_{2}(10 \mu \mathrm{M})$, Gli $(10 \mu \mathrm{M})$ or TEA $(1 \mathrm{mM})$, respectively, for $20 \mathrm{~min}$ prior to addition of $\mathrm{KCl}(60 \mathrm{mM})$, followed by cumulative addition of Sim.

A further experiment was performed in the absence of $\mathrm{Ca}^{2+}$, for which the rings were washed with $\mathrm{Ca}^{2+}$-free PSS. After incubation with or without $\operatorname{Sim}(10 \mu \mathrm{M})$ for $20 \mathrm{~min}$ in $\mathrm{Ca}^{2+}$-free PSS, $\mathrm{PE}(10 \mu \mathrm{M})$ was added to stimulate the release of intracellular $\mathrm{Ca}^{2+}$ and the contraction was recorded (8). In another experiment, the rings were washed with $\mathrm{Ca}^{2+}$-free PSS containing ethylene glycol-bis( $\beta$-aminoethyl ether)-N,N,N',N'-tetraacetic acid (EGTA; $100 \mu \mathrm{M}$; Sigma-Aldrich) and then rinsed with $\mathrm{Ca}^{2+}$-free PSS (without EGTA) containing $\mathrm{KCl}\left(60 \mathrm{mM} \mathrm{K}{ }^{+}\right.$. After incubation with or without $\operatorname{Sim}(10 \mu \mathrm{M})$ for $20 \mathrm{~min}$, $\mathrm{CaCl}_{2}(2 \mathrm{mM})$ was added to contract the artery rings (8).
All procedures involving animals were performed according to the Guide for the Care and Use of Laboratory Animals Published by the US National Institutes of Health (Publication no. 85-23, revised 1996) and the Guidelines for Animal Experimentation of Xi'an Medical University (Xi'an, China). The experimental protocols of the present study were approved by the Laboratory Animal Administration Committee of Xi'an Medical University (Xi'an, China).

Statistical analysis. Values are expressed as the mean \pm standard error of the mean. The effects of Sim are expressed as the percentage of relaxation with regard to the pre-contraction. For each agent, the negative logarithm of the concentration that caused $50 \%$ of the maximum response $\left(\mathrm{pD}_{2}\right)$ and the maximum relaxation $\left(\mathrm{E}_{\max } \%\right)$ were calculated. The unpaired Student's t-test was used to assess differences between groups. $\mathrm{P}<0.05$ was considered to indicate a statistically significant difference between groups. The analysis was performed using the SPSS 16.0 software (SPSS Inc., Chicago, IL, USA).

\section{Results}

Simrelaxes rat superior mesenteric arteries pre-constricted by $\mathrm{PE}$ or $\mathrm{KCl}$. In order to evaluate the vasodilative effects of Sim, the superior mesenteric artery rings of rats were pre-contracted with $\mathrm{PE}(10 \mu \mathrm{M})$ or $\mathrm{KCl}(60 \mathrm{mM})$, and once a plateau was attained, concentration-response curves were obtained by adding cumulative doses of Sim to the bath. The results showed that Sim concentration-dependently relaxed the superior mesenteric artery rings with endothelium pre-contracted by $\mathrm{PE}\left[\mathrm{E}_{\max }=51.05 \pm 4.09 \%\left(\mathrm{Sim}, 10^{-5} \mathrm{M}\right)\right.$; $\left.\mathrm{pD}_{2}=4.17 \pm 0.18\right]$ or $\mathrm{KCl}\left[\mathrm{E}_{\max }=41.65 \pm 1.32 \%\left(\mathrm{Sim}, 10^{-5} \mathrm{M}\right)\right.$; $\mathrm{pD}_{2}=3.55 \pm 0.10$ ] (Fig. $1 \mathrm{~A}$ and $\mathrm{B}$ ).

Role of the endothelium in Sim-induced relaxation of rat superior mesenteric arteries. The vasorelaxant effects of Sim on superior mesenteric artery rings with endothelium pre-contracted by $\mathrm{PE}(10 \mu \mathrm{M})$ were significantly stronger than those on artery rings without endothelium, with $\mathrm{E}_{\max }=49.55 \pm 3.67$ vs. $31.82 \pm 4.02 \%$ and $\mathrm{pD}_{2}=4.21 \pm 0.15$ vs. $0.35 \pm 0.15(\mathrm{P}<0.01)$. Moreover, vasorelaxation induced by Sim in artery rings with endothelium pre-contracted by $\mathrm{KCl}(60 \mathrm{mM})$ also was significantly stronger than in artery rings without endothelium $\left(\mathrm{E}_{\max }=40.79 \pm 1.49\right.$ vs. $31.68 \pm 1.76 \%$ and $\mathrm{pD}_{2}=3.56 \pm 0.09$ vs. $3.57 \pm 0.08 ; \mathrm{P}<0.01)$, while the effects were more marked in artery rings pre-contracted by PE (Fig. 2A and B).

To identify endothelial mediators associated with the vasodilative effects of Sim, the cyclooxygenase inhibitor Indo $(5 \mu \mathrm{M})$, the guanylate cyclase inhibitor ODQ $(10 \mu \mathrm{M})$ and the eNOS inhibitor L-NAME (100 $\mu \mathrm{M})$ were used, respectively. The results showed that in the artery rings with endothelium, L-NAME significantly inhibited the vasodilative effect of Sim, $\left(\mathrm{E}_{\max }=13.72 \pm 1.12\right.$ vs. $38.46 \pm 1.36 \% ; \mathrm{pD}_{2}=1.22 \pm 0.18$ vs. 3.72 \pm 0.09 ; $\mathrm{P}<0.01$ ) (Fig. 3A). However, ODQ and Indo did not significantly affect the relaxation induced by Sim in the artery rings with endothelium (Fig. 3B and C).

Role of $K^{+}$channels in Sim-induced relaxation of rat superior mesenteric arteries pre-constricted by $\mathrm{KCl}$. To assess the role of $\mathrm{K}^{+}$channels in Sim-induced vasorelaxation, artery rings 

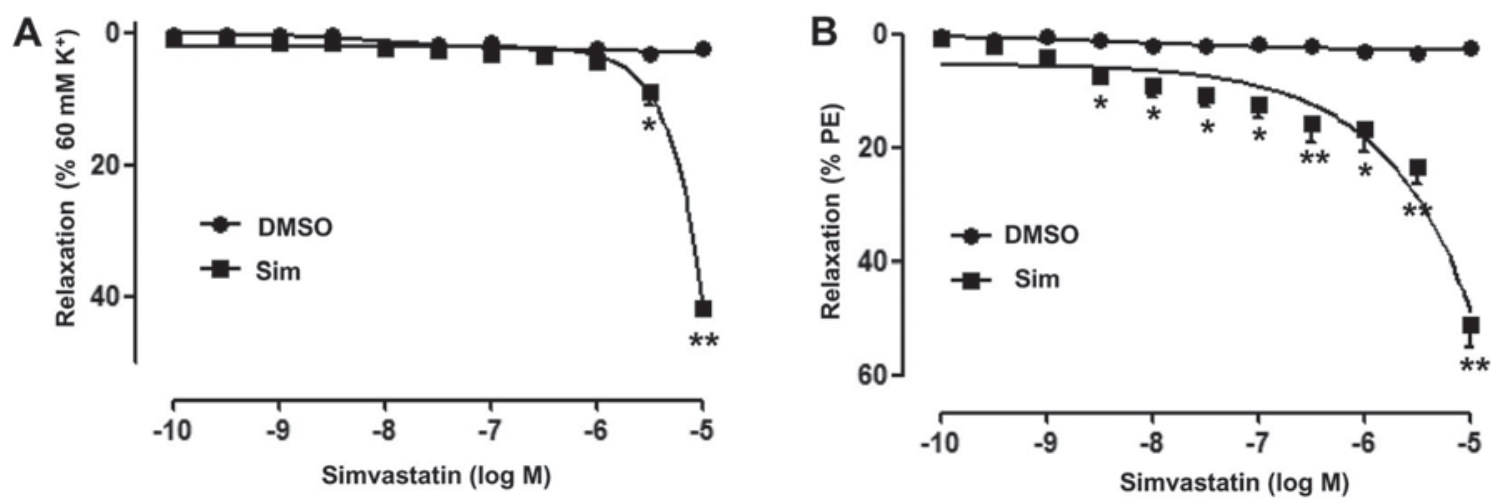

Figure 1. Vasodilatation effects of simvastatin (Sim) on endothelium-intact superior mesenteric arterial rings pre-contracted with (A) KCl (60 mM) or (B) PE $(10 \mathrm{mM})$. Values are expressed as the mean \pm standard error of the mean $(\mathrm{n}=6-8) .{ }^{*} \mathrm{P}<0.05 ;{ }^{* *} \mathrm{P}<0.01 \mathrm{vs}$. DMSO. DMSO, Dimethylsulfoxide; PE, phenylephrine hydrochloride.
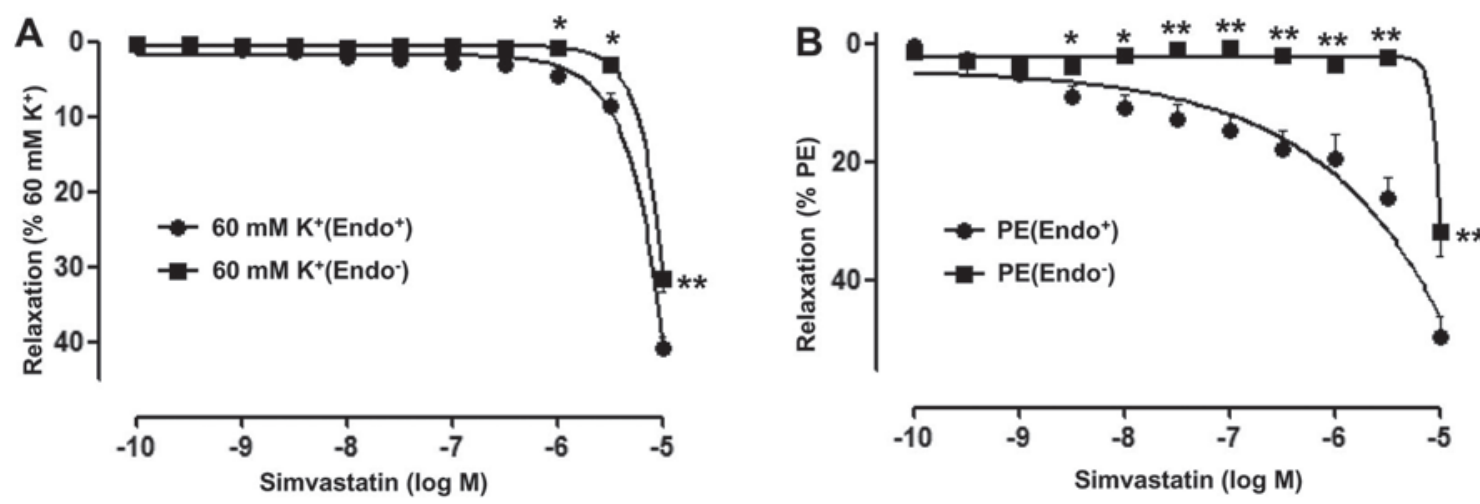

Figure 2. Vasodilatation effects of simvastatin (Sim) on endothelium-intact and endothelium-denuded superior mesenteric arterial rings pre-contracted with

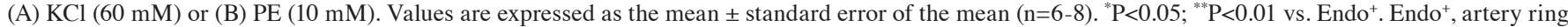
with endothelium; Endo; artery ring without endothelium; PE, phenylephrine hydrochloride.

ithout endothelium were pre-incubated with the $\mathrm{K}^{+}$channel blockers 4-AP $(100 \mu \mathrm{M}), \mathrm{BaCl}_{2}(10 \mu \mathrm{M})$, Gli $(10 \mu \mathrm{M})$ or TEA $(1 \mathrm{mM})$ for $20 \mathrm{~min}$ prior to addition of $\mathrm{KCl}(60 \mathrm{mM})$, following which Sim was added cumulatively. The results showed that 4-AP significantly reduced the relaxation induced by Sim in the artery rings without endothelium $\left(\mathrm{E}_{\max }=13.02 \pm 1.24\right.$ vs. $33.08 \pm 0.91 \%$ and $\mathrm{pD}_{2}=1.36 \pm 0.28$ vs. $\left.3.77 \pm 0.28 ; \mathrm{P}<0.01\right)$ (Fig. 4A). However, $\mathrm{BaCl}_{2}$, Gli and TEA did not significantly affect the relaxation induced by $\mathrm{Sim}$ in the artery rings without endothelium (Fig. 4B-D).

Effect of Sim on the calcium release by the sarcoplasmic reticulum in rat superior mesenteric arteries pre-constricted by $P E$. To clarify whether the relaxation induced by Sim was associated with intracellular $\mathrm{Ca}^{2+}$ release, an experiment in $\mathrm{Ca}^{2+}$-free PSS was performed. After incubation with or without $\operatorname{Sim}(10 \mu \mathrm{M})$ for $20 \mathrm{~min}, \mathrm{PE}(10 \mu \mathrm{M})$ was added to stimulate the release of intracellular $\mathrm{Ca}^{2+}$ and the contraction was recorded (8). The results showed that $\mathrm{PE}$ induced a transient contraction due to the release of intracellular $\mathrm{Ca}^{2+}$ into the $\mathrm{Ca}^{2+}$-free solution, while Sim did not attenuate this contraction $\left(\mathrm{E}_{\max }=5.84 \pm 1.25\right.$ vs. $5.93 \pm 0.97 \%$ ) (Fig. 5A).

Effect of Sim on extracellular $\mathrm{Ca}^{2+}$-induced contraction activated in rat superior mesenteric arteries pre-constricted by $\mathrm{KCl}$. To determine whether the inhibition of extracellular $\mathrm{Ca}^{2+}$ influx affected the relaxation induced by Sim, an experiment was performed in $\mathrm{Ca}^{2+}$-free PSS. Following immersion in $\mathrm{Ca}^{2+}$-free PSS containing $\mathrm{KCl}(60 \mathrm{mM})$, the rings were incubated with or without $\operatorname{Sim}(10 \mu \mathrm{M})$ for $20 \mathrm{~min}$, followed by contraction of the artery rings by addition of $\mathrm{CaCl}_{2}(2 \mathrm{mM})(8)$. The results showed that Sim significantly attenuated the contraction induced by addition of $\mathrm{CaCl}_{2}$ to the $\mathrm{Ca}^{2+}$-free PSS plus $\mathrm{KCl}\left(\mathrm{E}_{\max }=73.77 \pm 2.8\right.$ vs. 102.94 $\pm 3.98 \%$ ) (Fig. 5B). It was therefore suggested that Sim inhibits $\mathrm{Ca}^{2+}$ influx in the superior mesenteric artery.

\section{Discussion}

The present study revealed that Sim concentration-dependently relaxed the superior mesenteric artery rings with or without endothelium pre-contracted by $\mathrm{PE}$ or $\mathrm{KCl}$. The results suggested that Sim exerted its vasorelaxation effects via endothelium-dependent and -independent pathways. Moreover, the vasorelaxation induced by Sim was inhibited by L-NAME, while it was not affected by ODQ and Indo in artery rings with endothelium. In addition, Sim-induced vasorelaxation was inhibited by 4 -AP, while it was not affected by $\mathrm{Gli}, \mathrm{BaCl}_{2}$ and TEA in artery rings without endothelium. Finally, the vasorelaxation induced by Sim was 

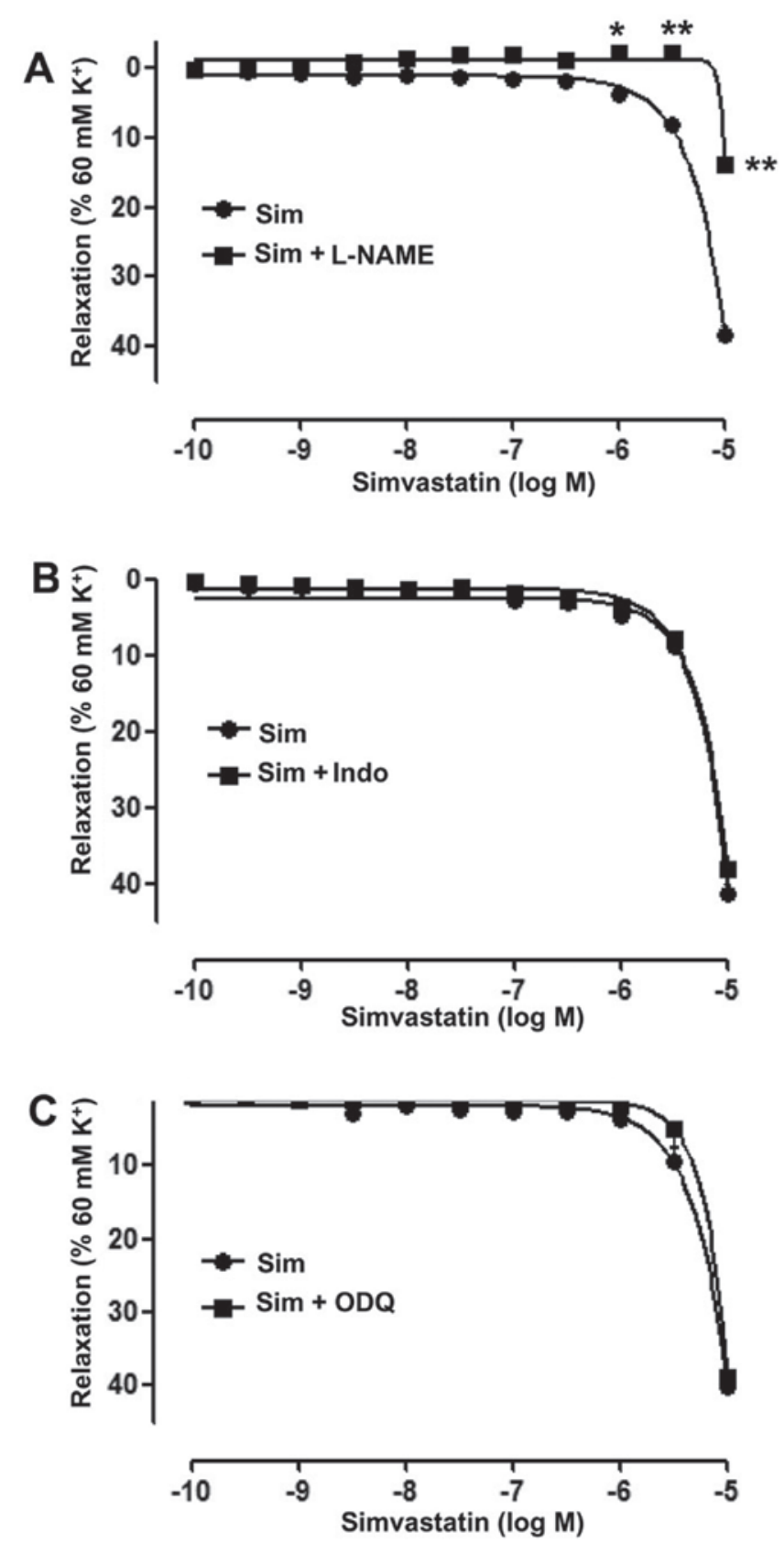

Figure 3. Vasodilatation effects of simvastatin ( $\mathrm{Sim}$ ) on endothelium-intact superior mesenteric arterial rings pre-contracted with $\mathrm{KCl}(60 \mathrm{mM})$ in the presence of (A) endothelial nitric oxide synthase inhibitor L-NAME (100 $\mu \mathrm{M})$, (B) guanylate cyclase inhibitor ODQ (10 $\mu \mathrm{M})$ or $(\mathrm{C})$ cyclooxygenase inhibitor Indo $(5 \mu \mathrm{M})$. Values are expressed as the mean \pm standard error of the mean $(\mathrm{n}=6-8) .{ }^{*} \mathrm{P}<0.05 ;{ }^{* * *} \mathrm{P}<0.01 \mathrm{vs}$. Sim. L-NAME, N $\omega$-nitro-L-arginine methyl ester; ODQ, $1 \mathrm{H}-[1,2,4]$ oxadiazolo[4,3-a]quinoxalin-1-one; Indo, indomethacin.

shown to be mediated through blockade of $\mathrm{Ca}^{2+}$ influx from extracellular medium.

Vascular endothelium located between vascular smooth muscle and circulating blood is known to be important in regulation of vascular tone. Vasorelaxation is mediated by vasorelaxant substances synthesized and released into the endothelium (9). In the present study, the relaxant effect induced by Sim was attenuated in the superior mesenteric artery rings without endothelium, suggesting that Sim also relaxes arteries through an endothelium-dependent pathway. Furthermore, the eNOS inhibitor L-NAME significantly reduced the vasorelaxation induced by Sim. However, cyclooxygenase inhibitor Indo and guanylate cyclase inhibitor ODQ did not affect the action of Sim. These results suggested that NO is involved in the relaxation of Sim in the superior mesenteric artery with endothelium, whereas the effect was not attributed to or prostanoids (Indo inhibits prostaglandin-endoperoxide synthase) or the cyclic guanosine monophosphate pathway. In accordance with the results of the present study, a previous study reported that in the aorta and small mesenteric artery, the efficacy of Sim was closely associated with the NO system in endothelial cells (2). However, the study also identified an association with prostanoids, which may therefore require clarification by further studies.

The present study further revealed that Sim also exerted vasorelaxant effect in superior mesenteric arteries without 

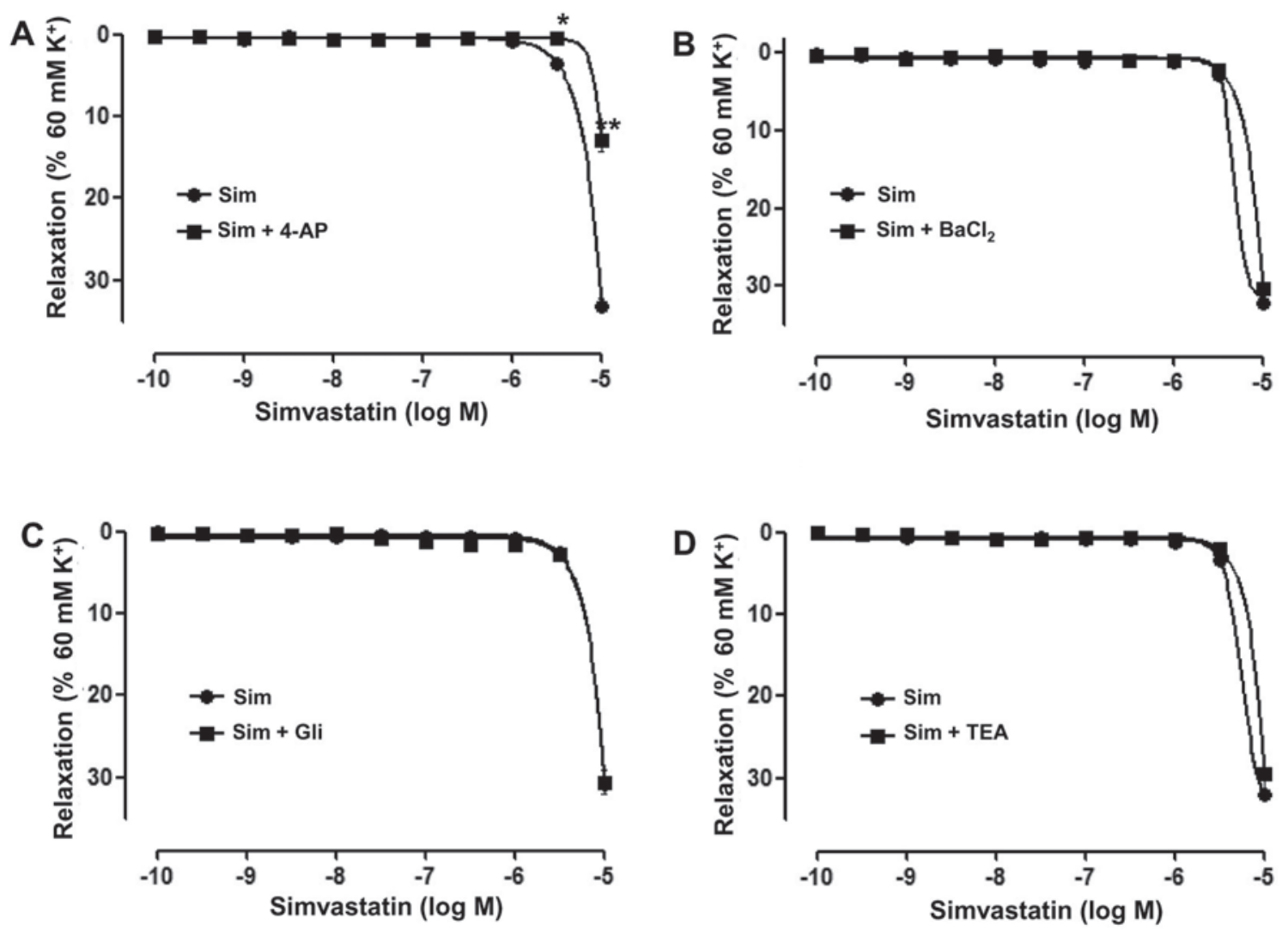

Figure 4. Vasodilatation effects of simvastatin ( $\mathrm{Sim}$ ) on endothelium-denuded superior mesenteric arteries. Vasodilatation effects of simvastatin on endothelium-denuded superior mesenteric arterial rings pre-contracted with $\mathrm{KCl}(60 \mathrm{mM})$ in the presence of $\mathrm{K}^{+}$channel blockers $(\mathrm{A}) 4-\mathrm{AP}(100 \mu \mathrm{M}),(\mathrm{B}) \mathrm{BaCl}{ }_{2}$ $(10 \mu \mathrm{M}),(\mathrm{C}) \mathrm{Gli}(10 \mu \mathrm{M})$ or $(\mathrm{D}) \mathrm{TEA}(1 \mathrm{mM})$. Values are expressed as the mean \pm standard error of the mean $(\mathrm{n}=6-8)$. 4-AP, 4-aminopyridine; Gli, glibenclamide; TEA, tetraethylammonium chloride; $\mathrm{BaCl}_{2}$, barium chloride dehydrate.
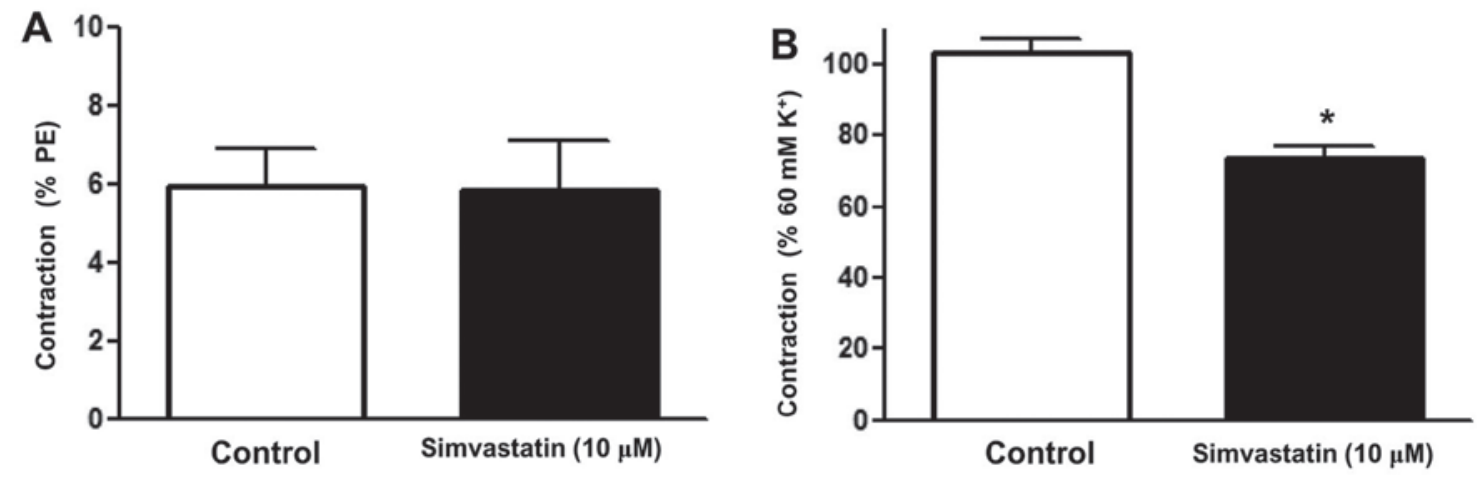

Figure 5. Inhibitory effects of simvastatin on (A) extracellular $\mathrm{Ca}^{2+}$ influx induced by $\mathrm{KCl}(60 \mathrm{mM})$ and (B) the sarcoplasmic reticulum $\mathrm{Ca}^{2+}$ release induced by $\mathrm{PE}$ in $\mathrm{Ca}^{2+}$-free solutionin endothelium-denuded superior mesenteric arterial rings. Values are expressed as the mean \pm standard error of the mean $(\mathrm{n}=6-8)$. ${ }^{*} \mathrm{P}<0.05$ vs. control. PE, phenylephrine hydrochloride.

endothelium, suggesting that Sim has a direct effect on vascular smooth muscle cells (VSMCs). The opening of $\mathrm{K}^{+}$channels in these cells causes hyperpolarization of the membrane potential and a decreased $\mathrm{Ca}^{2+}$ influx through voltage-operated $\mathrm{Ca}^{2+}$ channels, resulting in vasorelaxation $(10,11)$. Several types of $\mathrm{K}^{+}$channel have been identified in vascular smooth muscle, the most abundant ones being the large conductance $\mathrm{Ca}^{2+}$-activated $\mathrm{K}^{+}$channel, the voltage-sensitive $\mathrm{K}^{+}$channel, the adenosine triphosphate (ATP)-sensitive $\mathrm{K}^{+}$channel and inward-rectifyer $\mathrm{K}^{+}$channels. In order to detect the contribution of different types of $\mathrm{K}^{+}$channel to endothelium-independent relaxation induced by $\mathrm{Sim}$ in superior mesenteric artery rings, various $\mathrm{K}^{+}$channel-blocking agents were used, including the voltage-dependent $\mathrm{K}^{+}$channel blocker 4 -AP, inward-rectifying potassium channel blocker $\mathrm{BaCl}_{2}$, ATP-sensitive $\mathrm{K}^{+}$channel blocker Gli and $\mathrm{Ca}^{2+}$-activated $\mathrm{K}^{+}$ channel blocker TEA $(12,13)$. The results revealed that 4 -AP significantly inhibited the effect of Sim, indicating that the voltage-dependent $\mathrm{K}^{+}$channel was involved in the mechanism of the vasorelaxant action of $\mathrm{Sim}$. However, $\mathrm{BaCl}_{2}$, Gli and TEA did not affect the concentration-response curves of Sim, suggesting that the inward-rectifyer, ATP-sensitive and 
$\mathrm{Ca}^{2+}$-activated $\mathrm{K}^{+}$channels were not involved in Sim-mediated vasorelaxation.

Accumulation of intracellular calcium is associated with vascular smooth muscle contraction. Moreover, intracellular calcium levels may increase via extracellular $\mathrm{Ca}^{2+}$ influx through the receptor-operated or voltage-dependent calcium channels, as well as intracellular $\mathrm{Ca}^{2+}$ release (14). Contractions of VSMCs induced by $\mathrm{KCl}$ almost exclusively rely on $\mathrm{Ca}^{2+}$ influx through activation of voltage-sensitive channels (15), whereas PE-induced contractions are mediated via increasing the $\mathrm{Ca}^{2+}$ influx through receptor-operated (16) as well as voltage-sensitive channels (17). The results of the present study showed that Sim inhibited the contractile effects induced by $\mathrm{PE}$ or $\mathrm{KCl}$ on the superior mesenteric artery without endothelium, suggesting that Sim may interfere with receptor-operated as well as voltage-sensitive potassium channels. The release of intracellular stored $\mathrm{Ca}^{2+}$ is mainly regulated by the ryanodine and inositol triphosphate (IP3) receptor systems. In $\mathrm{Ca}^{2+}$-free medium, PE induces vascular contraction via inducing intracellular $\mathrm{Ca}^{2+}$ release through sarcoplasmic reticulum $\mathrm{Ca}^{2+}$ channels activated by IP3 (18). In the present study, Sim was shown to significantly inhibit $\mathrm{CaCl}_{2}$-induced contraction of superior mesenteric artery rings without endothelium in $\mathrm{Ca}^{2+}$-free PSS containing $\mathrm{KCl}$ $(60 \mathrm{mM})$, indicating that $\mathrm{Sim}$ is able to block $\mathrm{Ca}^{2+}$ influx. However, Sim did not inhibit the contraction triggered by $\mathrm{PE}$ in $\mathrm{Ca}^{2+}$-free PSS, suggesting that Sim does not affect $\mathrm{Ca}^{2+}$ mobilization from intracellular stores. It can therefore be concluded that in the superior mesenteric artery, Sim induces vasorelaxation via inhibition of extracellular calcium influx into VSMCs.

In conclusion, the results of the present study suggested that Sim induced relaxation of superior mesenteric arteries of rats through an endothelium-dependent pathway involving NO release, as well as an endothelium-independent pathway, opening of voltage-dependent $\mathrm{K}^{+}$channels and blockade of extracellular $\mathrm{Ca}^{2+}$ influx. These findings may support the further development of treatments for CVD.

\section{Acknowledgements}

The present study was supported by the National Natural Science Foundation of China (no. 81500350), the China Postdoctoral Science Foundation (no. 2015M582607) and the Shaanxi Postdoctoral Sustentation Fund, China (2015, second fund, no. 59).

\section{References}

1. Pedersen TR, Wilhelmsen L, Faergeman O, Strandberg TE, Thorgeirsson G, Troedsson L, Kristianson J, Berg K, Cook TJ, Haghfelt T, et al: Follow-up study of patients randomized in the Scandinavian simvastatin survival study $(4 \mathrm{~S})$ of cholesterol lowering. Am J Cardiol 86: 257-262, 2000.

2. Alvarez De Sotomayor M, Herrera MD, Marhuenda E and Andriantsitohaina R: Characterization of endothelial factors involved in the vasodilatory effect of simvastatin in aorta and small mesenteric artery of the rat. Br J Pharmacol 131: 1179-1187, 2000.

3. Mauro VF and MacDonald JL: Simvastatin: A review of its pharmacology and clinical use. DICP 25: 257-264, 1991.

4. Gryn SE and Hegele RA: Ezetimibe plus simvastatin for the treatment of hypercholesterolemia. Expert Opin Pharmacother 16: 1255-1262, 2015.

5. Robinson JG: Simvastatin: Present and future perspectives. Expert Opin Pharmacother 8: 2159-27, 2007.

6. Jiang JL, Jiang DJ, Tang YH, Li NS, Deng HW and Li YJ: Effect of simvastatin on endothelium-dependent vaso-relaxation and endogenous nitric oxide synthase inhibitor. Acta Pharmacol Sin 25: 893-901, 2004

7. Cao YX, Zhang W, He JY, He LC and Xu CB: Ligustilide induces vasodilatation via inhibiting voltage dependent calcium channel and receptor-mediated $\mathrm{Ca} 2+$ influx and release. Vascul Pharmacol 45: 171-176, 2006.

8. Zhu XM, Fang LH, Li YJ and Du GH: Endothelium-dependent and -independent relaxation induced by pinocembrin in rat aortic rings. Vascul Pharmacol 46: 160-165, 2007.

9. Rubanyi GM: The role of endothelium in cardiovascular homeostasis and diseases. J Cardiovasc Pharmacol 22 (Suppl 4): S1-S14, 1993.

10. Nelson MT and Quayle JM: Physiological roles and properties of potassium channels in arterial smooth muscle. Am J Physiol 268: C799-C822, 1995

11. Bolotina VM, Najibi S, Palacino JJ, Pagano PJ and Cohen RA: Nitric oxide directly activates calcium-dependent potassium channels in vascular smooth muscle. Nature 368: 850-853, 1994.

12. Brayden JE: Potassium channels in vascular smooth muscle. Clin Exp Pharmacol Physiol 23: 1069-1076, 1996.

13. Vergara C, Latorre R, Marrion NV and Adelman JP: Calcium-activated potassium channels. Curr Opin Neurobiol 8: 321-329, 1998.

14. Horowitz A, Menice CB, Laporte R and Morgan KG: Mechanisms of smooth muscle contraction. Physiol Rev 76: 967-1003, 1996.

15. Hirata S, Enoki T, Kitamura R, Vinh VH, Nakamura K and Mori K: Effects of isoflurane on receptor-operated $\mathrm{Ca} 2+$ channels in rat aortic smooth muscle. Br J Anaesth 81: 578-583, 1998.

16. Lee CH, Poburko D, Sahota P, Sandhu J, Ruehlmann DO and van Breemen C: The mechanism of phenylephrine-mediated $[\mathrm{Ca}(2+)](\mathrm{i})$ oscillations underlying tonic contraction in the rabbit inferior vena cava. J Physiol 534: 641-650, 2001.

17. Lee CN, Wong KL, Liu JC, Chen YJ, Cheng JT and Chan P: Inhibitory effect of stevioside on calcium influx to produce antihypertension. Planta Med 67: 796-799, 2001.

18. Eckert RE, Karsten AJ, Utz J and Ziegler M: Regulation of renal artery smooth muscle tone by alphal-adrenoceptors: Role of voltage-gated calcium channels and intracellular calcium stores. Urol Res 28: 122-127, 2000. 